\title{
Cytokine secretion from mononuclear cells cultured in vitro with starch-based polymers and poly-L-lactide
}

\author{
Alexandra P. Marques, ${ }^{1,2}$ Rui L. Reis, ${ }^{1,2}$ John A. Hunt ${ }^{3}$ \\ ${ }^{1} 3 B^{\prime}$ 's Research Group -Biomaterials, Biodegradables, and Biomimetics, University of Minho, Campus de Gualtar, \\ 4710-057 Braga, Portugal \\ ${ }^{2}$ Department of Polymer Engineering, University of Minho, Campus de Azurém, 4810-058 Guimarães, Portugal \\ ${ }^{3}$ Clinical Engineering, UKCTE, University of Liverpool, L69 3GA, United Kingdom
}

Received 17 February 2004; revised 15 June 2004; accepted 24 June 2004

Published online 7 October 2004 in Wiley InterScience (www.interscience.wiley.com). DOI: 10.1002/jbm.a.30155

\begin{abstract}
The cytokine network is one of the major controlling systems of the inflammatory process, driving the magnitude and duration of the host response against invading microorganisms, foreign materials, or altered internal stimuli. Pro- and antiinflammatory cytokines were quantified after in vitro culture of a mixed population of monocytes/macrophages and lymphocytes with biodegradable polymers. Different blends of starch-based polymers and their composites filled with hydroxyapatite were studied and compared with poly-L-lactide. Interleukin (IL)-1 $\beta$, IL-6, and tumour necrosis factor- $\alpha$ were investigated as the markers of immunological reactivity because they are known to act at the early stages of injury/invasion. Interferon- $\gamma$, recognized as a proinflammatory cytokine, although not present during early responses was also investigated. Contrarily, IL-4 derived from T lymphocytes, was investigated because it is an immunoregulator that counteracts some aspects of inflammation. T lymphocyte activation was also
\end{abstract}

determined by quantifying IL-2. The results support the hypothesis that different biodegradable polymers can affect mononuclear cell activation and the production of several cytokines associated with the inflammatory process. No IL-2 or interferon- $\gamma$ was found in the culture supernatants after 3 , 7 , and 14 days in the presence of any of the materials. IL-6 was detected in the highest amounts, for all the conditions, followed by tumour necrosis factor- $\alpha$. IL- $1 \beta$ was produced in very low amounts, being undetectable with some of the starch-based materials. IL-4 was the only cytokine that did not demonstrate any significant difference within this group of materials. Starch-based polymers and composites induced lower production of proinflammatory cytokines in comparison to poly-L-lactide. (C) 2004 Wiley Periodicals, Inc. J Biomed Mater Res 71A: 419-429, 2004

Key words: biodegradables; starch; polymers; macrophages; cytokines; in vitro

\section{INTRODUCTION}

It is now recognized that the failure of implanted medical devices can be associated with several inflammatory and infectious processes, with the overproduction of cytokines by persistent leukocytes potentially being a significant inherent factor in these. ${ }^{1-3}$ Adherent and activated mononuclear cells, monocytes/macrophages, and $\mathrm{T}$ lymphocytes produce inflammatory cytokines and chemokines that recruit other inflam-

Correspondence to: A. P. Marques, 3B's Research GroupBiomaterials, Biodegradables, and Biomimetics, University of Minho, Campus de Gualtar, 4710-057 Braga, Portugal

Contract grant sponsor: Portuguese Foundation for Science and Technology and the Portuguese Programme PRAXIS XXI; contract grant number: SFRH/BD1276/2000

Contract grant sponsor: FCT Foundation for Science and Technology, through funds from the POCTI and/or FEDER programmes

(c) 2004 Wiley Periodicals, Inc. matory cells to the site of implantation. ${ }^{1,4}$ Furthermore, cytokines may stimulate noninflammatory cells to secrete enzymes and cytokines that will compromise the success of the implant by altering cell phenotype and function. ${ }^{5,6}$

Mononuclear cells comprising monocytes and lymphocytes were cultured in vitro to determine the effect biomaterial surfaces had on the production and release of interleukin (IL)-1 $\beta$, IL-6, tumor necrosis factor (TNF)- $\alpha$ IL-2, IL-4, and interferon (IFN)- $\gamma$ which was analyzed by enzyme-linked immunosorbent assay (ELISA). The cytokines were selected considering their established roles in influencing the foreign body response to implanted materials by controlling local inflammation, cellular activation, and chemotaxis. ${ }^{7,8}$ It is recognized that antiinflammatory cytokines can also be present to act to reduce inflammation, ${ }^{8}$ balancing the effects of proinflammatory cytokines and maintaining homeostasis. IL-4 was investigated as an important antiinflammatory cytokine. 
TABLE I

Cytokine Production at 3-, 7-, and 14-Day Time Periods

\begin{tabular}{|c|c|c|c|c|c|c|c|c|c|c|c|c|c|c|c|c|c|c|}
\hline \multirow[b]{2}{*}{ Material } & \multicolumn{3}{|c|}{ IL-4 } & \multicolumn{3}{|c|}{ IL-6 } & \multicolumn{3}{|c|}{ IL-1 $\beta$} & \multicolumn{3}{|c|}{$\mathrm{TNF}-\alpha$} & \multicolumn{3}{|c|}{ IFN- $\gamma$} & \multicolumn{3}{|c|}{ IL-2 } \\
\hline & 3 & 7 & 14 & 3 & 7 & 14 & 3 & 7 & 14 & 3 & 7 & 14 & 3 & 7 & 14 & 3 & 7 & 14 \\
\hline SEVA-C & + & + & + & + & + & + & + & - & - & + & + & + & - & - & - & - & - & - \\
\hline SEVA-C $+10 \%$ HA & + & + & + & + & + & + & - & - & - & + & + & + & - & - & - & - & - & - \\
\hline SEVA-C $+20 \%$ HA & + & + & + & + & + & + & - & + & - & + & + & + & - & - & - & - & - & - \\
\hline SEVA-C + 30\% HA & + & + & + & + & + & + & - & - & - & + & + & + & - & - & - & - & - & - \\
\hline SPCL & + & + & + & + & + & + & + & + & + & + & + & + & - & - & - & - & - & - \\
\hline $\mathrm{SPCL}+10 \% \mathrm{HA}$ & + & + & + & + & + & + & + & + & - & + & + & + & - & - & - & - & - & - \\
\hline SPCL + 20\% HA & + & + & + & + & + & + & + & + & + & + & + & + & - & - & - & - & - & - \\
\hline $\mathrm{SPCL}+30 \% \mathrm{HA}$ & + & + & + & + & + & + & + & + & - & + & + & + & - & - & - & - & - & - \\
\hline SCA & + & + & + & + & + & + & + & + & + & + & + & + & - & - & - & - & - & - \\
\hline $\mathrm{SCA}+10 \% \mathrm{HA}$ & + & + & + & + & + & + & - & - & - & + & + & + & - & - & - & - & - & - \\
\hline $\mathrm{SCA}+20 \% \mathrm{HA}$ & + & + & + & + & + & + & + & - & - & + & + & + & - & - & - & - & - & - \\
\hline $\mathrm{SCA}+30 \% \mathrm{HA}$ & + & + & + & + & + & + & - & - & - & + & + & + & - & - & - & - & - & - \\
\hline PS & + & + & + & + & + & + & + & + & + & + & + & + & - & - & - & - & - & - \\
\hline PLLA & + & + & + & + & + & + & + & + & + & + & + & + & - & - & - & - & - & - \\
\hline
\end{tabular}

The in vitro model was composed of different cell types, which produce specific cytokines. IL-1 $\beta$ although produced by many different cell types including neutrophils, natural killer cells, and $\mathrm{B}$ and $\mathrm{T}$ lymphocytes, is produced in great abundance by blood monocytes and tissue macrophages. ${ }^{9}$

Mononuclear phagocytes also produce IL-6, one of the earliest cytokines of the inflammatory process and a major inducer of acute phase proteins. ${ }^{10,11}$

Lymphocytes, present in the mononuclear population cultured in direct contact with the materials, also produce IL-6 and IL-1 $\beta$. Nonetheless, IL-2, ${ }^{12}$ IL- $4,{ }^{13}$ and IFN- $\gamma^{14,15}$ are specifically lymphocyte-derived cytokines and their quantification can help to determine the potential roles of lymphocytes in direct contact with materials.

TNF- $\alpha$ is produced in large amounts by activated mononuclear phagocytes, macrophages, and lymphocytes $^{16,17}$ and for that reason represents a valuable activation marker.

Besides the induced level of stimulation of each population of cells, the model enabled the analysis of interactions between the cytokines themselves. IL-1 $\beta$ is known to have multiple roles in the regulation of normal tissue repair and chronic inflammation. It stimulates the production of acute phase-reactant proteins ${ }^{11}$ and has the ability to activate wound healing cells (fibroblasts), lymphocytes, and monocytes., ${ }^{9,18}$ IL-6 is a cytokine with pleiotropic activities produced by a variety of cells including fibroblasts, endothelial cells, mononuclear phagocytes, neutrophils, hepatocytes, and $\mathrm{T}$ and B lymphocytes. ${ }^{19}$ This cytokine can down-regulate fibroblast and endothelial cell growth and alternatively it can promote the growth and differentiation of monocytes and lymphocytes. ${ }^{19}$ The lymphocyte-derived cytokines have significant influence in the monocyte/macrophage population synergizing and/or reducing the effect of the cytokines produced by those cells. In particular, in response to IL-2, macrophages will synthesize IL-1 which further activates T cells to produce more IL- 2 to activate more macrophages in a feed-back cycle. ${ }^{20} \mathrm{IL}-4$, secreted predominantly by $\mathrm{T}$ helper (Th)-2 lymphocytes, ${ }^{13}$ inhibits production of IL- 1 and TNF- $\alpha$ by activated monocytes. ${ }^{21}$ IL-4 has also been shown to promote monocyte/macrophage fusion to form foreign body giant cells. ${ }^{22}$ IFN- $\gamma$ exerts important activities on both monocyte/macrophage and lymphocytes, which generally results in macrophage activation and $\mathrm{T}$ cell differentiation toward a Th-1 type of immune response. ${ }^{23}$

In this work, the potential of starch-based materials, previously proposed for a wide range of biomedical applications, ${ }^{24-27}$ to induce cytokine production by mononuclear cells in vitro was investigated and compared with poly-L-lactide (PLLA) (Table I).

\section{MATERIALS AND METHODS}

\section{Materials}

The materials studied were:

1. a 50:50 (wt \%) blend of corn starch and ethylene vinyl alcohol (SEVA-C) (Novamont, Italy);

2. SEVA-C reinforced with $10 \%, 20 \%$, and $30 \%$ (wt) hydroxyapatite (HA) (Plasma Biotal, UK);

3. a 50:50 (wt \%) blend of corn starch and cellulose acetate (SCA) (Novamont, Italy);

4. SCA reinforced with $10 \%, 20 \%$, and $30 \%$ (wt) HA;

5. a 30:70 (wt \%) blend of corn starch and polycaprolactone (SPCL) (Novamont, Italy); and

6. SPCL reinforced with $10 \%, 20 \%$, and $30 \%$ (wt) HA.

In the composites, the average size of $90 \%$ of the HA particles was found to be $<6.5 \mu \mathrm{m}$ (laser granulometry analysis). 
PLLA (Purac Biochem BV, The Netherlands), being the gold standard for biodegradables in biomedical applications, was used as a biodegradable control material and polystyrene (PS) coverslips (Sarstedt, UK) as a reference material.

All the materials were processed into circular samples $(\varnothing$ $1 \mathrm{~cm}$ ) by injection molding under optimized processing conditions.

\section{Mononuclear cell isolation and culture}

A mixed population of lymphocytes and monocytes/macrophages was isolated from healthy volunteers. Blood was layered onto lymphocyte separation medium (LymphoSep; ICN Biomedicals, Cleveland, $\mathrm{OH}$ ) and centrifuged at $400 \mathrm{~g}$ for $25 \mathrm{~min}$ at $4^{\circ} \mathrm{C}$. The cell suspension was washed twice with phospate-buffered saline at $400 \mathrm{~g}$ for $5 \mathrm{~min}$ at $4^{\circ} \mathrm{C}$ and the final cell concentration controlled and taken into cell culture conditions with Medium 199 (GIBCO BRL, Rockville, MD) supplemented with $1 \%$ antibiotics (Sigma Chemical Co., St. Louis, MO), 10\% fetal calf serum (GIBCO BRL Life Technologies, Rockville, MD), and $0.2 \%$ fungizone (Sigma).

Cells were seeded in direct contact with the polymers for 3,7 , and 14 days at a concentration of $5 \times 10^{4}$ cells $/ \mathrm{mL}, 1 \mathrm{~mL}$ per well.

\section{Cytokine quantification}

After each time period, plates were centrifuged to avoid cells in suspension and $200 \mu \mathrm{L}$ of the supernatant of each well was transferred to a new 96-well plate and kept at $-80^{\circ} \mathrm{C}$, previously shown to be unaffected by up to three freeze-thaw cycles, ${ }^{28}$ for analysis using ELISA. The following cytokines were quantified by enzyme immunoassay. Human IFN- $\gamma$ with a minimal detectable dose of $<4 \mathrm{pg} / \mathrm{mL}$, human IL-2 with a minimal detectable dose of $<5.1 \mathrm{pg} / \mathrm{mL}$, human IL-4 with a minimal detectable dose of $<2.0 \mathrm{pg} / \mathrm{mL}$, human IL-6 with a minimal detectable dose of $<2 \mathrm{pg} / \mathrm{mL}$, human IL-1 $\beta$ with a minimal detectable dose of $1 \mathrm{pg} / \mathrm{mL}$, and human TNF- $\alpha$ with a minimal detectable dose of 1.7 $\mathrm{pg} / \mathrm{mL}$. All ELISA kits were obtained from Biosource International, Inc. (Camarillo, CA).

For each cytokine, all samples were tested in duplicate on each plate and repeated at least three times in independent experiments except for IFN- $\gamma$ and IL-2, which were found to be undetectable after two experiments and stopped. ELISA plates were read using a LUCY 1 luminometer plate reader at wavelength $450 \mathrm{~nm}$ (Bio-Stat; Biochem Immunosystems, Italy). For each measurement, a standard concentration curve was generated according to the indication of the assay kit and used to calculate the concentration of released cytokine.

\section{Statistical analysis}

The data were statistically analyzed by a one-way analysis of variance using a Tukey-HDS post hoc test. ${ }^{29}$ The results were compared for all the materials at the different times of culture, and between themselves at each time of culture. If probability values were $<0.05$, differences observed were considered to be statistically significant (Tables II-IV) .

\section{RESULTS}

IL-6 was detected in the highest amounts, for all the conditions, followed by TNF- $\alpha$. IL-1 $\beta$ was produced in lower amounts and was undetectable with some of the starch-based materials. No IL-2 or IFN- $\gamma$ was produced at any of the tested times of culture in the presence of any of the materials.

There were differences in the amount of released cytokines with respect to culture time, the amount decreasing with increasing culture time. In a previous study, ${ }^{30}$ the same experimental conditions were used for the quantification of the intracellular lactate dehydrogenase of cells adherent to the surface of the materials. That data showed that the number of adherent cells varied according to the material, although not statistically significantly. The results demonstrated that the cytokine production was affected by the material and not by the adherent cell number.

\section{IL-4}

The amount of IL-4 detected varied between 16 and $29 \mathrm{pg} / \mathrm{mL}$. No significant differences were observed except in the case of SCA $+20 \%$ HA [Fig. 1(c)]. The levels of IL-4 tended to increase with the culture period in the presence of composites, reaching values after 7 and 14 days of culture that were statistically different from those obtained for 3 days of culture. There was no correlation between the IL-4 released and the different starch-based blends or with the percentage of HA that was reinforcing each of them.

\section{IL-6}

In the case of IL-6, the results obtained were complex and influenced by the type of material and the presence of ceramic reinforcement. It was possible to observe that the amount of IL-6 released decreased with the time of culture for most of the materials although these differences were not statistically significant.

IL-6 was the cytokine detected in highest quantity in the harvested supernatants and varied between about 1200 and $70 \mathrm{pg} / \mathrm{mL}$. PLLA and PS were the two materials that induced the highest IL-6 release. The results obtained in the presence of SEVA-C and com- 
TABLE II

Statistical Summary for IL-6 Expression for Different Pairs of Polymers (Statistically Significant $p$ Values)

\begin{tabular}{|c|c|c|c|c|c|c|c|c|c|c|c|}
\hline $\begin{array}{l}\text { Time } \\
\text { Culture }\end{array}$ & Material & SEVA-C & $\begin{array}{c}\text { SEVA-C + } \\
10 \% \mathrm{HA}\end{array}$ & $\begin{array}{c}\text { SEVA-C + } \\
20 \% \text { HA }\end{array}$ & $\begin{array}{c}\text { SEVA-C + } \\
30 \% \text { HA }\end{array}$ & SPCL & $\begin{array}{c}\text { SPCL + } \\
10 \% \\
\text { HA }\end{array}$ & $\begin{array}{c}\mathrm{SPCL}+ \\
20 \% \\
\mathrm{HA}\end{array}$ & SCA & PS & PLLA \\
\hline \multirow[t]{12}{*}{3 Days } & SEVA-C & & & & & & & & & 0 & 0 \\
\hline & SEVA-C + 10\% HA & & & & & & & & & 0 & 0 \\
\hline & SEVA-C $+20 \%$ HA & & & & & & & & & 0 & 0 \\
\hline & SEVA-C $+30 \% \mathrm{HA}$ & & & & & & & & & 0 & 0 \\
\hline & SPCL & 0.004 & 0 & 0 & 0 & & & & & & 0.006 \\
\hline & SPCL + 10\% HA & 0.007 & 0 & 0 & 0 & & & & & & 0.004 \\
\hline & SPCL + 20\% HA & 0 & 0 & 0 & 0 & & & & & & 0.045 \\
\hline & SPCL + 30\% HA & & 0.01 & 0 & 0 & & & & & 0.013 & 0.001 \\
\hline & SCA & 0.022 & 0 & & & & & & & 0.032 & 0.001 \\
\hline & $\mathrm{SCA}+10 \% \mathrm{HA}$ & & & & & 0.012 & 0.018 & 0.001 & & 0 & 0 \\
\hline & $\mathrm{SCA}+20 \% \mathrm{HA}$ & & & & & 0.027 & 0.041 & 0.003 & & 0 & 0 \\
\hline & $\mathrm{SCA}+30 \% \mathrm{HA}$ & & & & & 0.007 & 0.011 & 0.001 & 0.037 & 0 & 0 \\
\hline \multirow{12}{*}{7 Days } & SEVA-C & & & & & & & & & 0 & 0 \\
\hline & SEVA-C $+10 \%$ HA & & & & & & & & & 0 & 0 \\
\hline & SEVA-C + 20\% HA & & & & & & & & & 0 & 0 \\
\hline & SEVA-C $+30 \%$ HA & & & & & & & & & 0 & 0 \\
\hline & SPCL & 0.017 & 0 & 0 & 0 & & & & & 0.005 & \\
\hline & SPCL + 10\% HA & 0.007 & 0 & 0 & 0 & & & & & 0.012 & \\
\hline & SPCL + 20\% HA & 0.011 & 0 & 0 & 0 & & & & & 0.007 & \\
\hline & $\mathrm{SPCL}+30 \% \mathrm{HA}$ & & 0.001 & 0 & 0 & & & & & 0 & \\
\hline & SCA & 0.046 & 0 & 0 & 0 & & & & & 0.002 & \\
\hline & $\mathrm{SCA}+10 \% \mathrm{HA}$ & & & & & 0.015 & 0.006 & 0.010 & 0.042 & 0 & 0 \\
\hline & $\mathrm{SCA}+20 \% \mathrm{HA}$ & & & 0.050 & & 0.031 & 0.012 & 0.021 & & 0 & 0 \\
\hline & $\mathrm{SCA}+30 \% \mathrm{HA}$ & & & & & 0.014 & 0.006 & 0.009 & 0.040 & 0 & 0 \\
\hline \multicolumn{12}{|l|}{14} \\
\hline \multirow[t]{12}{*}{ Days } & SEVA-C & & & & & & & & & 0 & 0 \\
\hline & SEVA-C + 10\% HA & & & & & & & & & 0 & 0 \\
\hline & SEVA-C $+20 \%$ HA & & & & & & & & & 0 & 0 \\
\hline & SEVA-C $+30 \% \mathrm{HA}$ & & & & & & & & & 0 & 0 \\
\hline & SPCL & & & 0.032 & 0.042 & & & & & 0.025 & 0.010 \\
\hline & SPCL + 10\% HA & & & 0.029 & 0.038 & & & & & 0.028 & 0.011 \\
\hline & SPCL + $20 \%$ HA & & 0.025 & 0.012 & 0.016 & & & & & & 0.024 \\
\hline & $\mathrm{SPCL}+30 \% \mathrm{HA}$ & & & & & & & & & 0.007 & 0.003 \\
\hline & SCA & & & 0.041 & & & & & & 0.020 & 0.008 \\
\hline & $\mathrm{SCA}+10 \% \mathrm{HA}$ & & & & & & & & & 0 & 0 \\
\hline & $\mathrm{SCA}+20 \% \mathrm{HA}$ & & & & & & & & & 0 & 0 \\
\hline & $\mathrm{SCA}+30 \% \mathrm{HA}$ & & & & & & & & & 0 & 0 \\
\hline
\end{tabular}

posites [Fig. 2(a)] and in the presence of SCA and composites [Fig. 2(c)], after 3, 7, or 14 days of culture were found to be statistically different from those obtained for these two control materials, except SCA after 7 days ( $p<0.05$ only when compared with PS). For SPCL and composites [Fig. 2(b)], these materials induced a release of IL-6 similar to that of PS after 3 days (except SPCL $+30 \%$ HA) and comparable with PLLA after 7 days. After 14 days, the levels of IL-6 induced by SPCL and composites reached lower values, and these were significantly different from PS and PLLA and therefore closer to those obtained for SCA and composites except in the case of SPCL $+20 \%$ HA which was still comparable with PS.

SEVA-C and composites seemed to stimulate less leukocyte activation [Fig. 2(a)]. The amounts of IL-6 detected in the presence of those materials were lower than those obtained with any of the other materials without any differences being measured between polymer and composites although a decrease was observed with increasing HA percentages. After 3 days of culture, these were found to be statistically different from SPCL and its composites with 10\% HA, 20\% HA, and SCA, as well as the results between SPCL + 30\% HA and SEVA-C composites, only changing after 7 days when comparing SEVA-C $+30 \%$ HA and SCA $+20 \%$ HA. After 14 days of culture, the results for SEVA and composites and SCA became closer and only SEVA-C $+20 \%$ HA was found to induce significant IL-6 production when compared with SCA. Also when compared with SPCL, and its composites with 10\% HA and $20 \%$ HA, only SEVA-C reinforced with $20 \%$ HA and $30 \%$ HA were found to be different. Furthermore, 
TABLE III

Statistical Summary for IL-1 $\beta$ Expression for Different Pairs of Polymers (Statistically Significant $p$ Values)

\begin{tabular}{|c|c|c|c|c|c|}
\hline $\begin{array}{l}\text { Time } \\
\text { Culture }\end{array}$ & Material & $\begin{array}{c}\text { SPCL } \\
+ \\
20 \% \\
\text { HA }\end{array}$ & SCA & PS & PLLA \\
\hline \multirow[t]{12}{*}{3 Days } & SEVA-C & & 0 & 0 & 0 \\
\hline & SEVA-C $+10 \%$ HA & 0.017 & 0 & 0 & 0 \\
\hline & SEVA-C + $20 \%$ HA & 0.017 & 0 & 0 & 0 \\
\hline & SEVA-C + 30\% HA & 0.049 & 0 & 0 & 0 \\
\hline & SPCL & & 0 & 0 & 0 \\
\hline & SPCL $+10 \%$ HA & & 0 & 0 & 0 \\
\hline & SPCL + $20 \%$ HA & & 0 & 0 & 0 \\
\hline & SPCL + 30\% HA & & 0 & 0 & 0 \\
\hline & SCA & & & 0 & 0 \\
\hline & $\mathrm{SCA}+10 \% \mathrm{HA}$ & & 0 & 0 & 0 \\
\hline & $\mathrm{SCA}+20 \% \mathrm{HA}$ & & 0 & 0 & 0 \\
\hline & $\mathrm{SCA}+30 \% \mathrm{HA}$ & 0.017 & 0 & 0 & 0 \\
\hline \multirow[t]{11}{*}{7 Days } & SEVA-C & & 0.025 & 0 & 0.01 \\
\hline & SEVA-C $+10 \% \mathrm{HA}$ & & 0.010 & 0 & 0 \\
\hline & SEVA-C $+20 \%$ HA & & & 0 & 0.010 \\
\hline & SEVA-C $+30 \%$ HA & & 0.010 & 0 & 0 \\
\hline & SPCL & & & 0.022 & \\
\hline & SPCL + 10\% HA & & & 0 & 0.002 \\
\hline & SPCL + $20 \%$ HA & & & 0.001 & 0.030 \\
\hline & $\begin{array}{l}\text { SPCL + 30\% HA } \\
\text { SCA }\end{array}$ & & & 0 & 0.003 \\
\hline & $\mathrm{SCA}+10 \% \mathrm{HA}$ & & 0.010 & 0 & 0 \\
\hline & $\mathrm{SCA}+20 \% \mathrm{HA}$ & & 0.020 & 0 & 0.01 \\
\hline & $\mathrm{SCA}+30 \% \mathrm{HA}$ & & 0.010 & 0 & 0 \\
\hline
\end{tabular}

the SEVA-C $+10 \%$ HA result was also different from SPCL $+20 \%$ HA.

Following SEVA-C and composites, SCA and respective composites were the materials that induced more production of IL-6 [Fig. 2(c)]. Again, the same trend, in terms of the amount of released cytokine and percentage of HA was observed. However, some statistical differences were found after 3 days of culture between SCA and the composite with 30\% HA and after 7 days of culture between SCA and the composites with $10 \%$ HA and $30 \% \mathrm{HA}$. Furthermore, at 3 and 7 days of culture, it was observed that the results in the presence of SCA composites were different from the results in the presence of SPCL composites.

In the presence of SPCL and composites, in contrast with the other starch-based materials, it was possible to detect and quantify almost three times more IL-6. The amount of HA did not seem to have any influence [Fig. 2(b)].

\section{IL-1 $\beta$}

IL-1 $\beta$ production was material dependent and in some cases with the time of culture. SEVA-C and composites, as well as the SCA composites did not show any differences with the time of culture. However, SCA and PS showed significant decreases in IL-1 $\beta$ production with increasing time of culture. The amount of cytokine released in the presence of SPCL with 10\% HA and 20\% HA also showed that tendency, although in the case of the composite with $10 \% \mathrm{HA}$, the difference was only statistically significant after 14 days. IL-1 $\beta$ was detected in very low amounts after contact with starch-based materials when compared with the control materials (Fig. 3). In fact, after 3 and 7 days of culture, all the materials, except for SCA and SPCL $(p<0.05$ only when compared with PS) showed a significantly different result from PS and PLLA. After 14 days of culture, almost no IL-1 $\beta$ was detected in the supernatants. Comparing the amounts of IL- $1 \beta$ released in the presence of starchbased materials after 3 days of culture, SCA induced production in significantly different quantities [Fig. 3(c)]. That difference was only maintained after 7 days of culture for SEVA-C and SEVA-C composites with 10\% HA and 30\% HA [Fig. 3(a)] and for SCA composites [Fig. 3(c)].

After incubation of cells with SPCL composites, HA was found not to reduce the amount of produced IL-1 $\beta$, when compared with the non-reinforced polymers. The amount was only different after 3 days and only between SPCL $+20 \%$ HA and SEVA-C composites and SCA $+30 \%$ HA.

\section{TNF- $\alpha$}

The results obtained for TNF- $\alpha$ demonstrated significant variations according to the type of material, in some cases also being influenced by the percentage of ceramic filler and by the time of culture. Again, as for IL-6, the general tendency was a reduction in release with time of culture for most of the materials. For some of the materials, there were detectable differences after 7 and 14 days of culture (SEVA-C $+10 \%$ HA, PLLA); others only revealed variations in the amount of cytokine after 14 days in culture (SEVA-C, SEVA-C + 20\% HA, SPCL $+10 \%$ HA and PS).

The level of TNF- $\alpha$ detected in the supernatants of the cultures was between 3 and $190 \mathrm{pg} / \mathrm{mL}$ (Fig. 4). The higher amounts of TNF- $\alpha$ were detected in the presence of PLLA and PS. After 3 days of culture with all starch-based materials and composites, the released TNF- $\alpha$ was found to be significantly different from PS and PLLA, except for SPCL $+30 \%$ HA and SCA $(p<$ 0.05 only when compared with PLLA). After 7 days, differences were observed for SEVA-C and composites, SPCL, and SCA composites whereas the results for SPCL reinforced with 10\% HA and 30\% HA were similar to PS. After 14 days of culture, only the SEVA-C composites were found to be different from the control materials. However, the amount of cyto- 
TABLE IV

Statistical Summary for TNF- $\alpha$ Expression for Different Pairs of Polymers (Statistically Significant $p$ Values)

\begin{tabular}{|c|c|c|c|c|c|c|c|c|c|}
\hline $\begin{array}{l}\text { Time } \\
\text { Culture }\end{array}$ & Material & SEVA-C & $\begin{array}{c}\text { SEVA-C + } \\
10 \% \text { HA }\end{array}$ & $\begin{array}{c}\text { SEVA-C + } \\
20 \% \text { HA }\end{array}$ & $\begin{array}{c}\text { SEVA-C + } \\
30 \% \text { HA }\end{array}$ & $\begin{array}{c}\text { SPCL + } \\
30 \% \\
\text { HA }\end{array}$ & SCA & PS & PLLA \\
\hline \multirow[t]{12}{*}{3 Days } & SEVA-C & & & & & & 0.011 & 0 & 0 \\
\hline & SEVA-C + $10 \%$ HA & & & & & & 0 & 0 & 0 \\
\hline & SEVA-C $+20 \%$ HA & & & & & & 0 & 0 & 0 \\
\hline & SEVA-C + 30\% HA & 0.017 & & & & & 0 & 0 & 0 \\
\hline & SPCL & & & 0.033 & 0.003 & & 0.049 & 0 & 0 \\
\hline & SPCL $+10 \% \mathrm{HA}$ & & 0.005 & 0 & 0 & & & 0.034 & 0 \\
\hline & SPCL + $20 \% \mathrm{HA}$ & & 0.008 & 0 & 0 & & & 0.023 & 0 \\
\hline & SPCL + 30\% HA & & 0.01 & 0 & 0 & & & & 0.001 \\
\hline & SCA & & & & & & & & 0.007 \\
\hline & $\mathrm{SCA}+10 \% \mathrm{HA}$ & & & & & 0.020 & 0.003 & 0 & 0 \\
\hline & $\mathrm{SCA}+20 \% \mathrm{HA}$ & & & & & 0.022 & 0.003 & 0 & 0 \\
\hline & $\mathrm{SCA}+30 \% \mathrm{HA}$ & & & & & 0.014 & 0.002 & 0 & 0 \\
\hline \multirow[t]{12}{*}{7 Days } & SEVA-C & & & & & & 0.021 & 0 & 0 \\
\hline & SEVA-C + $10 \%$ HA & & & & & & 0.001 & 0 & 0 \\
\hline & SEVA-C + 20\% HA & & & & & & 0 & 0 & 0 \\
\hline & SEVA-C + 30\% HA & & & & & & 0 & 0 & 0 \\
\hline & SPCL & & & & & & & 0.010 & 0.001 \\
\hline & SPCL + 10\% HA & & 0.045 & 0.007 & 0.005 & & & & 0.028 \\
\hline & SPCL + 20\% HA & & 0.022 & 0.003 & 0.002 & & & & \\
\hline & $\mathrm{SPCL}+30 \% \mathrm{HA}$ & & & 0.009 & 0.002 & & & & 0.023 \\
\hline & SCA & & & & & & & & \\
\hline & $\mathrm{SCA}+10 \% \mathrm{HA}$ & & & & & & & 0.007 & 0.001 \\
\hline & $\mathrm{SCA}+20 \% \mathrm{HA}$ & & & & & & & 0.014 & 0.002 \\
\hline & $\mathrm{SCA}+30 \% \mathrm{HA}$ & & & & & & & 0.003 & 0 \\
\hline \multicolumn{10}{|l|}{14} \\
\hline \multirow[t]{12}{*}{ Days } & SEVA-C & & & & & & & & 0.004 \\
\hline & SEVA-C + 10\% HA & & & & & & & 0.012 & 0.001 \\
\hline & SEVA-C + 20\% HA & & & & & & & 0.002 & 0 \\
\hline & SEVA-C + 30\% HA & & & & & & 0.040 & 0.001 & 0 \\
\hline & SPCL & & & & & & & & 0.026 \\
\hline & $\mathrm{SPCL}+10 \% \mathrm{HA}$ & & & & & & & & \\
\hline & SPCL $+20 \%$ HA & & & & & & & & \\
\hline & SPCL + 30\% HA & & & & 0.043 & & & & \\
\hline & SCA & & & & & & & & \\
\hline & $\mathrm{SCA}+10 \% \mathrm{HA}$ & & & & & & & & 0.021 \\
\hline & $\mathrm{SCA}+20 \% \mathrm{HA}$ & & & & & & & & 0.013 \\
\hline & $\mathrm{SCA}+30 \% \mathrm{HA}$ & & & & & & & & 0.014 \\
\hline
\end{tabular}

kine released during contact with SEVA-C, SPCL, and SCA composites was still different from PLLA.

Analyzing the amount of TNF- $\alpha$ in the presence of SEVA-C and composites, a similar trend to IL- 6 was observed: lower levels were detected when compared with all the other materials [Fig. 4(a)]. Comparing the polymer and composites, it was found that the amount of cytokine released decreased with increasing percentages of HA. Furthermore, after 3 days of culture, the amount of TNF- $\alpha$ detected in the presence of SEVA-C was found to be significantly different for the result obtained with SEVA-C + 30\% HA.

Comparing the results obtained for SEVA-C and composites with all the other materials, after 3 and 7 days, statistically significant differences were found with SCA. After 14 days, only the difference between SEVA-C + $30 \% \mathrm{HA}$ and SCA remained. SEVA-C composites were found to be significantly different from SPCL composites after 3 and 7 days, except for SPCL $+30 \%$ HA after 7 days $(p<0.05$ only when compared with SEVA-C with $20 \% \mathrm{HA}$ and $30 \% \mathrm{HA}$ ). The amount of TNF- $\alpha$ released in contact with SEVA-C $+30 \%$ HA was also found to be different from the SPCL composite with the same amount of HA at the 14-day time period.

When comparing all the starch-based materials, higher amounts of TNF- $\alpha$ were released in the presence of SPCL and composites [Fig. 4(b)]. In this case, and contrary to SEVA and its composites, increasing percentages of HA resulted in increasing amounts of cytokine release. In fact, and in addition to the statistical differences reported after 3 days in culture, TNF- $\alpha$ released in the presence of SPCL was found to be different from the amount detected in the presence of SEVA-C with 20\% HA and 30\% HA. 
Once again, and in agreement with IL-6 quantification, the level of TNF- $\alpha$ produced in contact with SCA composites was lower than that detected for SPCL composites and higher than the amount obtained for SEVA-C composites. However, in the case of the unreinforced polymer (SCA), the amounts detected were the highest when compared with SEVA-C or SPCL.

Contrary to any of the other starch-based blends, the presence of HA in the starch blend with cellulose acetate induced a decrease in the amount of TNF- $\alpha$ production, although the percentage of ceramic had

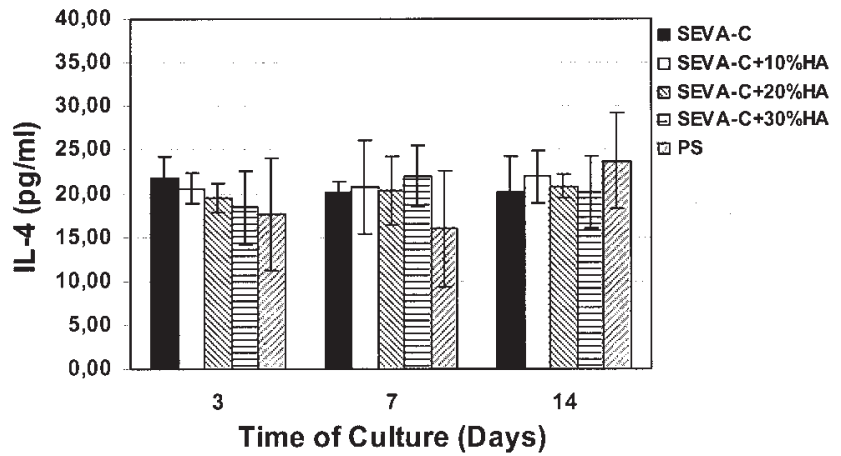

(a)

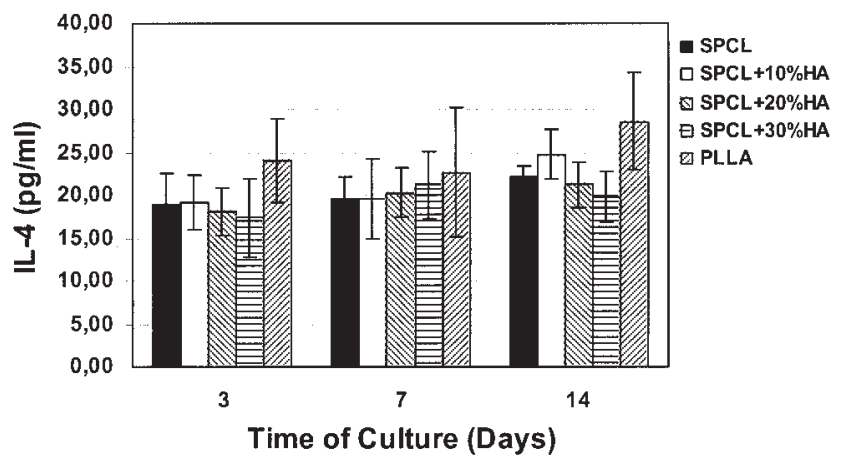

(b)

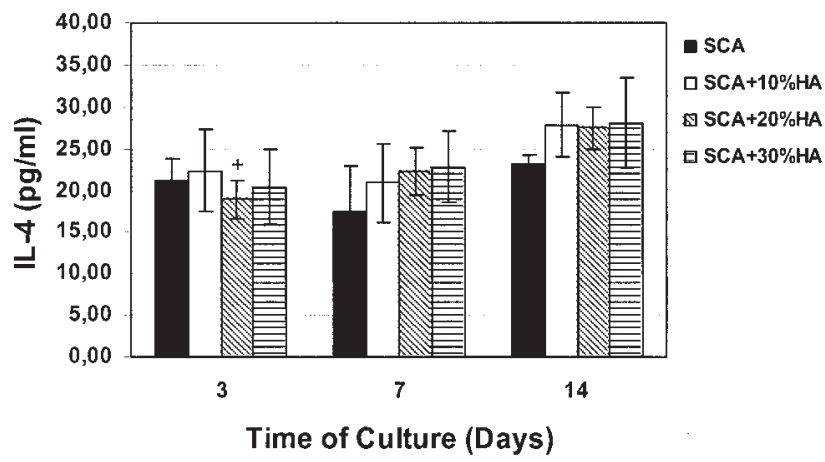

(c)

Figure 1. IL-4 release from monocytes/macrophages and lymphocytes when in culture with (a) SEVA-C and respective composites with HA and PS, (b) SPCL and respective composites with HA and PLLA, (c) SCA and respective composites with HA, for 3, 7, and 14 days. Data represent mean \pm standard deviation, $n \geq 3 .{ }^{+}$Significant difference with 7 and 14 days of culture.

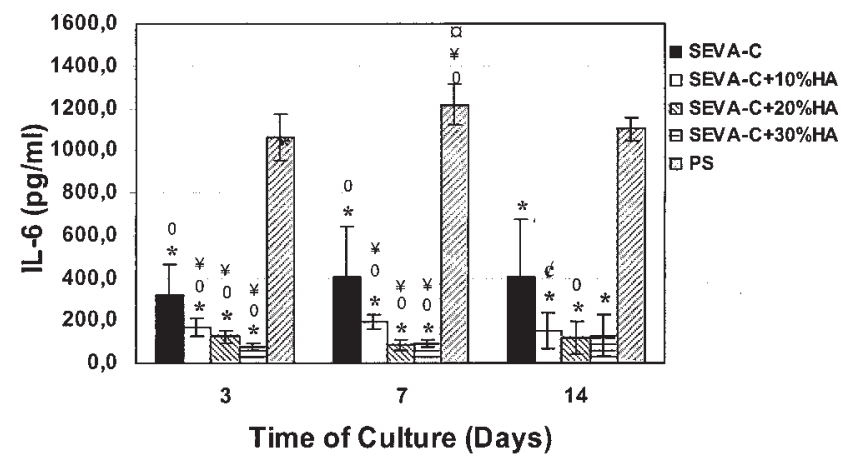

(a)

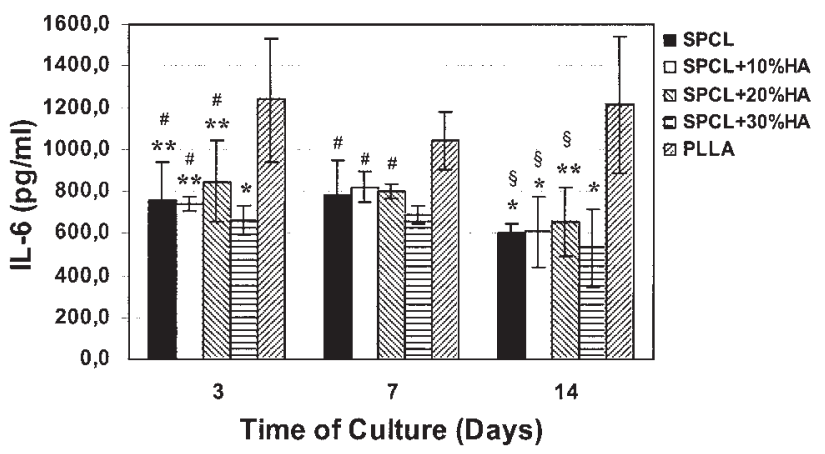

(b)

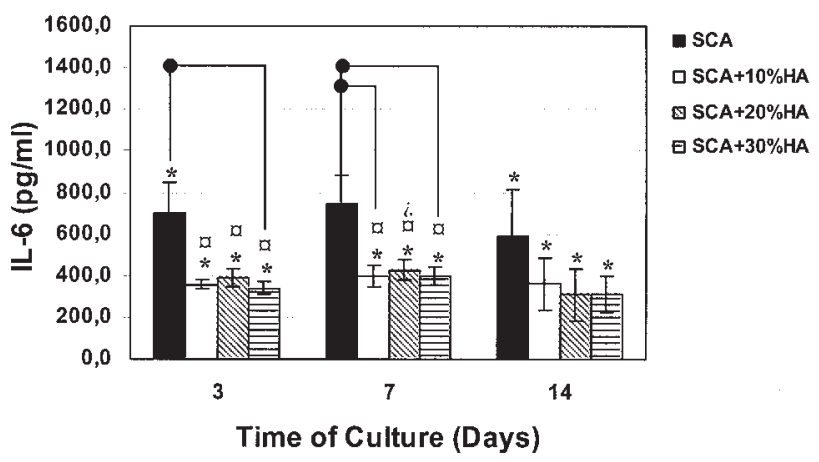

(c)

Figure 2. IL-6 release from monocytes/macrophages and lymphocytes when in culture with (a) SEVA-C and respective composites with HA and PS, (b) SPCL and respective composites with HA and PLLA, (c) SCA and respective composites with $\mathrm{HA}$, for 3,7 , and 14 days. Data represent mean \pm standard deviation, $n \geq 3$. ${ }^{*}$ Significant difference when compared with PLLA and PS. ${ }^{* *}$ Significant difference when compared with PLLA. ${ }^{0}$ Significant difference when compared with SCA. "Significant difference when compared with SEVA-C and respective com-

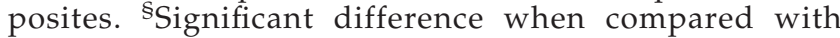
SEVA composites with $20 \%$ and $30 \%$ HA. 'Significant difference when compared with SEVA-C $+20 \%$ HA. ${ }^{\circ}$ Significant difference when compared with SPCL and respective composites with $10 \%$ and $20 \%$ HA. ${ }^{\varnothing}$ Significant difference when compared with SPCL $+20 \%$ HA. ${ }^{¥}$ Significant difference when compared with SPCL $+30 \%$ HA. - - Significant difference between the connected bars. 
no influence. After 3 days of culture, the results obtained for SCA were found to be different from those obtained for composites. In addition, the results for composites were also different from the result obtained for SPCL + 30\% HA.

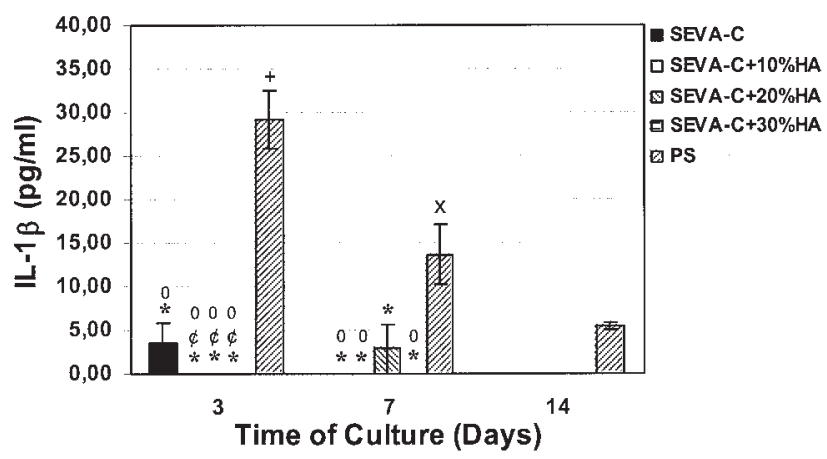

(a)

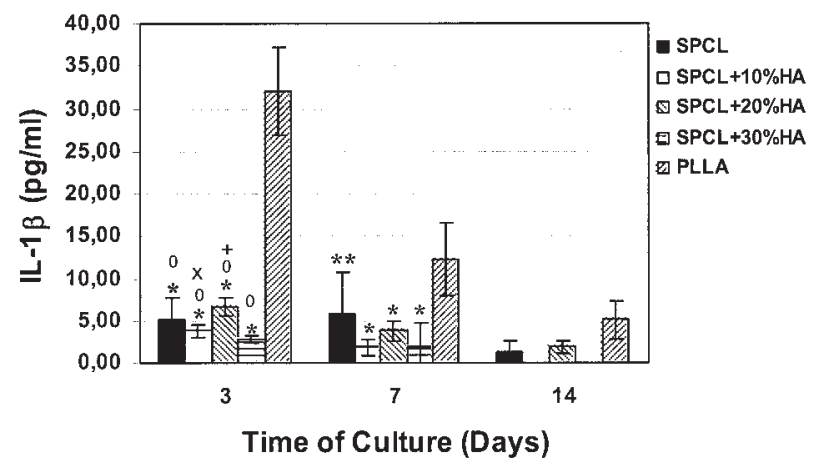

(b)

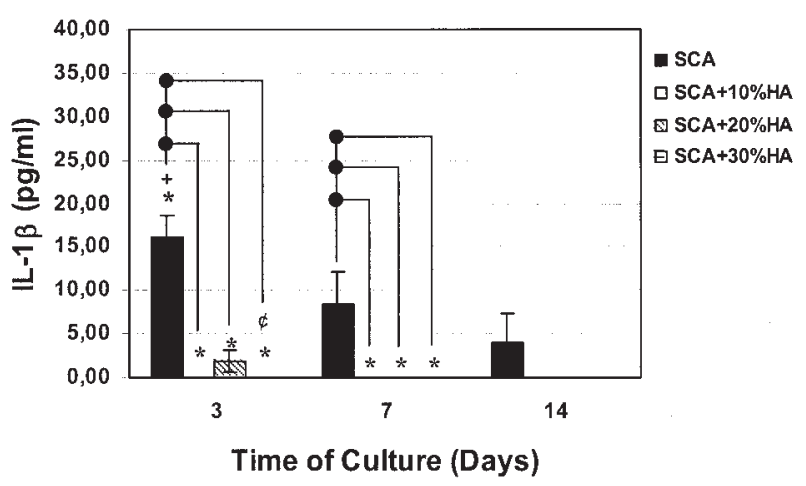

(c)

Figure 3. IL-1 $\beta$ release from monocytes/macrophages and lymphocytes when in culture with (a) SEVA-C and respective composites with HA and PS, (b) SPCL and respective composites with HA and PLLA, (c) SCA and respective composites with HA, for 3, 7, and 14 days. Data represent mean \pm standard deviation, $n \geq 3$. *Significant difference when compared with PLLA and PS. **Significant difference when compared with PS. ${ }^{0}$ Significant difference when compared with SCA. ${ }^{\circledR}$ Significant difference when compared with SPCL $+20 \%$ HA. $\bullet-$ Significant difference between the connected bars. ${ }^{+}$Significant difference with 7 and 14 days of culture. ${ }^{\times}$Significant difference with 14 days of culture.

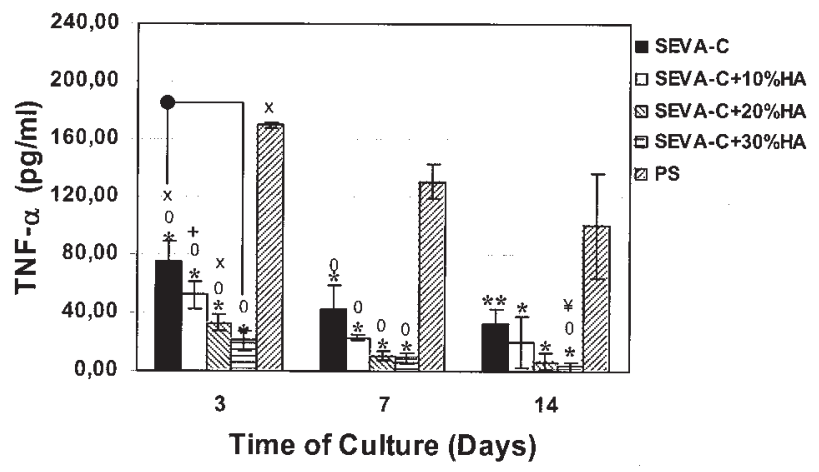

(a)

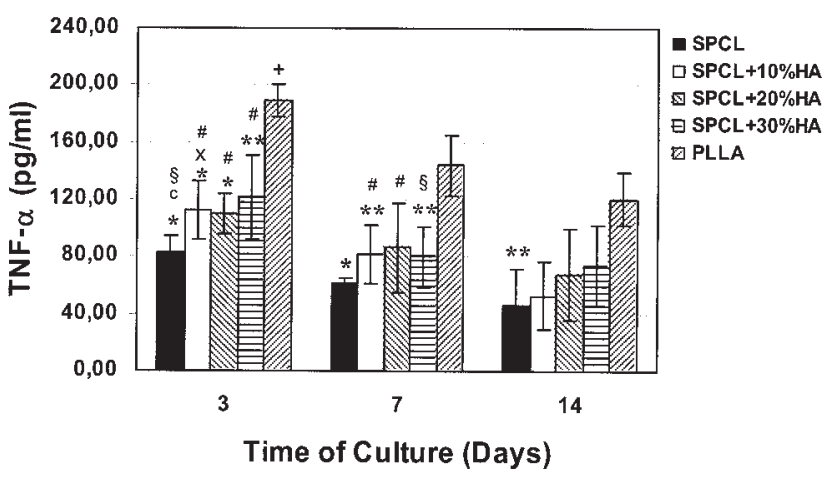

(b)

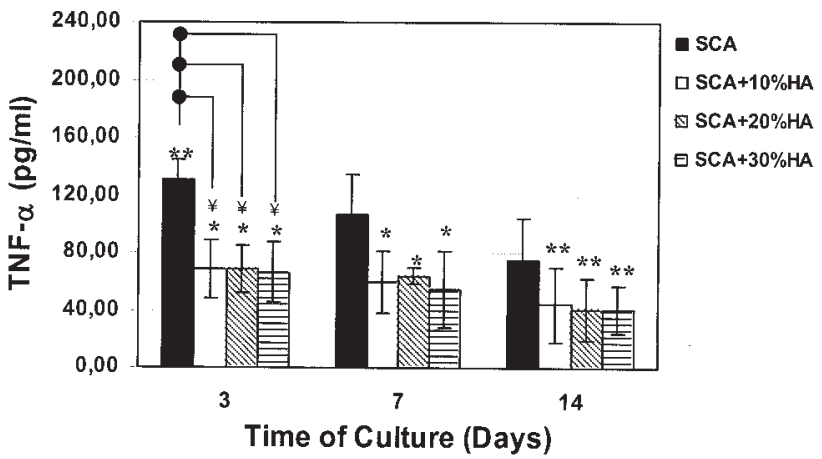

(c)

Figure 4. TNF- $\alpha$ release from monocytes/macrophages and lymphocytes when in culture with (a) SEVA-C and respective composites with HA and PS, (b) SPCL and respective composites with HA and PLLA, (c) SCA and respective composites with HA, for 3,7 , and 14 days. Data represent mean \pm standard deviation, $n \geq 3$. *Significant difference when compared with PLLA and PS. **Significant difference when compared with PLLA. ${ }^{0}$ Significant difference when compared with SCA. "Significant difference when compared with SEVA-C composites. ${ }^{\text {SSignificant difference }}$ when compared with SEVA composites with $20 \%$ and $30 \% \mathrm{HA}$. ${ }^{¥}$ Significant difference when compared with SPCL $+30 \%$ HA. - - Significant difference between the connected bars. ${ }^{+}$Significant difference with 7 and 14 days of culture. ${ }^{\times}$Significant difference with 14 days of culture. 


\section{DISCUSSION}

Several studies ${ }^{31,32}$ have demonstrated that leukocytes attach and adhere to biomaterial surfaces. Upon adherence, those cells undergo morphological and physiological changes such as membrane perturbation and frustrated phagocytosis that can lead to cell activation and the release of chemical mediators such as cytokines. ${ }^{1,32-34}$ These cytokines can influence the initiation, duration, and resolution of the host response to injury, which is determined by the prolonged presence of the biomaterial. ${ }^{35}$

It has been reported that there are several factors that modulate the cellular activation process and mediate production of cytokines. Surface physical and chemical properties ${ }^{36-38}$ and adhesion specific signals ${ }^{31,36,37}$ are believed to have an important role; however, some authors ${ }^{39}$ defend that unknown factors also might be involved in monocyte differentiation and activation.

IL-1 $\beta$, TNF- $\alpha$, and IL- 6 were considered as markers for polymer-induced macrophage activation and it was shown that starch-based polymers and composites significantly reduce the release of these cytokines compared with PS and PLLA.

It was reported by Chomyszyn-Gajewska et al. ${ }^{40}$ that in the absence of serum, PLLA did not stimulate the release of IL-6, IL-12, and TNF- $\alpha$. However, after an initial incubation with serum, the release of IL-6 and IL-12 increased dramatically, which was related to the fact that the studied materials have no surface ligands recognizable by macrophages to trigger the synthesis of certain cytokines.

Activation of monocytes may occur after adhesion to a surface, or alternatively, through cell-cell or cellmediator interaction without adhesion to the surface. Studies with tissue culture PS found the greatest release of IL-1 $\beta$, IL-6, and TNF- $\alpha$ by monocytes/macrophages cultured in contact with that polymer in comparison with other polymers. Ung et al. ${ }^{41}$ assumed that the surface treatment performed in tissue culture plates to achieve maximum adhesion leads to increasing activation of monocytes/macrophages.

In the present work, cytokines were determined in the cell supernatant, therefore the detected levels reflected the combination of adherent and nonadherent cells. We have previously demonstrated (article in press) ${ }^{30}$ that the number of cells adhered to the surface of PS was lower than in the case of certain starchbased polymers and composites. Therefore, we may speculate that nonadherent cells had a major contribution in the production of proinflammatory cytokines in the presence of PS.

Khouw et al. ${ }^{42}$ found that applying monoclonal antibodies against IFN- $\gamma$ inhibited the foreign body reaction to hexamethylenediisocyanate which indicated the important role played by that cytokine in the inflammatory process as a well as the possibility to modulate its activity. Some authors ${ }^{43}$ defend that macrophages, besides natural killer cells and T lymphocytes, are also able to produce IFN- $\gamma$; however, T cell inhibition results in a foreign body reaction delay which could suggest an active role of $\mathrm{T}$ lymphocytes in the host response.

Although the polymers in this study were cultured with a mixed population of monocytes/macrophages and lymphocytes, $\mathrm{T}$ cells did not demonstrate significant activation.

TNF- $\alpha$ has a crucial role in the inflammatory response, resulting in a great number of cases in osteolysis around the implant. ${ }^{1,2,5,6}$ Several studies found that this cytokine can be produced at much higher levels than IL- 6 and IL-1 $\beta$ by macrophages in the presence of polymer or metal particles. ${ }^{44-46}$

The regulation of TNF- $\alpha$ production is complex and can be inhibited by IL-4, IL-10, or IL-13 and greatly enhanced by IFN- $\gamma$. Levings and Schrader ${ }^{47}$ proved that IL-4-mediated inhibition of TNF- $\alpha$ release occurs by a transcription factor STAT6-dependent mechanism. However, in the presence of IFN- $\gamma$, another and physiologically more important STAT6-independent mechanism is active. In this study, no IFN- $\gamma$ was detected and the amount of produced IL- 4 was similar in the presence of all materials. Therefore, it might be considered that IL- 4 has no additional effect in the TNF- $\alpha$ released in the presence of the studied materials.

TNF- $\alpha$ and IL- 6 were released in higher amounts and with an almost similar distribution, which may reflect monocyte differentiation, because IL- 6 has been implicated in monocyte differentiation ${ }^{19}$ and TNF- $\alpha$ has been described as an autocrine regulator of macrophage differentiation. ${ }^{48}$

IL-1 $\beta$ is produced in response to many stimuli which include bacterial lipopolysaccharide, numerous microbial products, cytokines (TNF- $\alpha$, IFN- $\gamma$, granulocyte-macrophage colony-stimulating factor, and IL2), T cell/antigen presenting cell interactions, and immune complexes and was found to stimulate the production of IL-6 in peripheral blood monocytes. ${ }^{49}$

The IL-1 $\beta$ production detected was zero or minimal in the presence of some materials, suggesting resting or nonstimulated monocytes and macrophages. It seems that no cross effect was happening between TNF- $\alpha$ release and IL- $1 \beta$ production or that the amount of released TNF- $\alpha$ was not enough to stimulate IL-1 $\beta$ production. Furthermore, the amount of detected IL-6 was significantly higher than the amount of IL-1 $\beta$.

It has been reported that the hydrophilic/hydrophobic character of a polymer surface, characterized by the contact angle, may influence cytokine production from monocytes ${ }^{36}$; however, other factors may 
also be important, because other studies have reported that similar compositions and contact angles result in different IL-1 production. ${ }^{39}$ Yun et al. ${ }^{37}$ reported that specific surfaces such as hydrophilic and neutral surfaces may be the least likely to adhere and activate monocytes.

In fact, starch-based polymers have different surface wettabilities. The more hydrophilic surfaces (SCA) induced higher TNF- $\alpha$ and IL-1 $\beta$ production whereas SPCL, the polymer with the most hydrophobic surface, together with SCA showed the highest secretion of IL-6. It could be speculated that, in the case of IL-6, hydrophilicity is not the most important factor for monocyte/macrophage activation, whereas the TNF- $\alpha$ and IL-1 $\beta$ production seems to be dependent on and more evident in more hydrophilic surfaces.

Protein adsorption can directly influence the activation of monocytes and macrophages on a surface in a time-dependent manner. DeFife et al $^{31}$ found that fibrinogen and immunoglobulin $\mathrm{G}$ preadsorption resulted in different IL-1 $\beta$, IL-6, and TNF- $\alpha$ concentrations in the supernatants depending on the polymers and the time of culture. Previous studies with starchbased polymers and human serum demonstrated that SPCL was the polymer that presented the highest levels of protein adsorption. ${ }^{50}$ If protein adsorption implies cell adhesion and consequently cell activation, the results obtained, in terms of IL- $1 \beta$ and TNF- $\alpha$ production, did not support this theory.

Concerning the HA reinforcement, although some authors report improved performance of those implants in terms of femoral remodeling and bone density, ${ }^{51,52}$ others report that ceramic coatings may produce particulate wear debris and osteolysis. ${ }^{53,54}$ Ninomiya et al. ${ }^{5}$ reported that HA enhanced the production of IL-1 $1 \beta$, IL- 6 , and TNF- $\alpha$ by human fibroblasts in vitro. In the present study, HA resulted in a significant reduction of those inflammatory cytokines, especially in the case of SCA and for shorter culture periods. SEVA-C composites also showed a lower effect in the secretion of IL- 6 and TNF- $\alpha$ whereas, in the case of SPCL composites, the only evident effect was the secretion of TNF- $\alpha$; in this case, HA induced higher production of TNF- $\alpha$.

\section{CONCLUSIONS}

The isolation and culture of a mixed population of mononuclear cells enabled the evaluation of the inflammatory potential.

Starch-based polymers and composites did not elicit a very strong reaction from immune system cells in vitro, demonstrated by a lower production of cytokines when compared with PLLA biodegradable material.
HA reinforcement resulted in lower cell activation, potentially enabling better mechanical properties to be combined with reduced levels of cytokine production.

The authors gratefully acknowledge the Portuguese Foundation for Science and Technology and the Portuguese Programme PRAXIS XXI for awarding a Ph.D. Grant to A. P. Marques.

\section{References}

1. Jiranek WA, Machado M, Jasty M, Jevsevar D, Wolfe HJ, Goldring SR, Goldberg MJ, Harris WH. Production of cytokines around loosened cemented acetabular components. Analysis with immunohistochemical techniques and in situ hybridization. J Bone Joint Surg Am 1993;75(6):863-879.

2. Blaine TA, Rosier RN, Puzas JE, Looney RJ, Reynolds PR, Reynolds SD, O'Keefe RJ. Increased levels of tumor necrosis factor-alpha and interleukin-6 protein and messenger RNA in human peripheral blood monocytes due to titanium particles. J Bone Joint Surg Am 1996;78(8):1181-1192.

3. Konttinen YT, Ju JW, Patiala H, Imai S, Waris V, Li TF, Goodman SB, Nordsletten L, Santavirta S. Cytokines in aseptic loosening of total hip replacement. Curr Orthop 1997;11:40-47.

4. Suzuki K, Onodera S, Matsuno T, Kaneda K, Nishihira J. Identification of macrophage migration inhibitory factor in synovial membranes of loosened total joint replacement. Biochem Mol Biol Int 1996;39(3):529-537.

5. Ninomiya JT, Struve JA, Stelloh CT, Toth JM, Crosby KE. Effects of hydroxyapatite particulate debris on the production of cytokines and proteases in human fibroblasts. J Orthop Res 2001;19(4):621-628.

6. Ishimi $\mathrm{Y}$, Miyaura $\mathrm{C}$, Jin $\mathrm{CH}$, Akatsu T, Abe E, Nakamura $\mathrm{Y}$, Yamaguchi A, Yoshiki S, Matsuda T, Hirano T, et al. IL-6 is produced by osteoblasts and induces bone resorption. J Immunol 1990;145(10):3297-3303.

7. Moldawer LL. Biology of proinflammatory cytokines and their antagonists. Crit Care Med 1994;22(7):S3-7.

8. Borish LC, Steinke JW. 2. Cytokines and chemokines. J Allergy Clin Immunol 2003;111(2 Suppl):S460-475.

9. Dinarello CA. Interleukin-1. Cytokine Growth Factor Rev 1997 8(4):253-265.

10. Heinrich PC, Castell JV, Andus T. Interleukin-6 and the acute phase response. Biochem J 1990;265(3):621-636.

11. Ramadori G, Christ B. Cytokines and the hepatic acute-phase response. Semin Liver Dis 1999;19(2):141-155.

12. Goronzy JJ, Gold KN, Weyand CM. T-cell derived lymphokines as regulators of chronic inflammation: potential targets for immunomodulation? Am J Ther 1996;3(2):109-114.

13. Seder RA, Paul WE. Acquisition of lymphokine-producing phenotype by CD4 ${ }^{+}$T cells. Annu Rev Immunol 1994;12:635673.

14. Young HA, Hardy KJ. Interferon-gamma: producer cells, activation stimuli, and molecular genetic regulation. Pharmacol Ther 1990;45(1):137-151.

15. Young HA, Hardy KJ. Role of interferon-gamma in immune cell regulation. J Leukoc Biol 1995;58(4):373-381.

16. Aggarwal BB, Kohr WJ, Hass PE, Moffat B, Spencer SA, Henzel WJ, Bringman TS, Nedwin GE, Goeddel DV, Harkins RN. Human tumor necrosis factor. Production, purification, and characterization. J Biol Chem 1985;260(4):2345-2354.

17. Wallach D, Varfolomeev EE, Malinin NL, Goltsev YV, Kovalenko AV, Boldin MP. Tumor necrosis factor receptor and Fas signaling mechanisms. Annu Rev Immunol 1999;17:331367. 
18. Piazuelo E, Jimenez P, Lanas A, Garcia A, Esteva F, Sainz R. Platelet-derived growth factor and epidermal growth factor play a major role in human colonic fibroblast repair activities. Eur Surg Res 2000;32(3):191-196.

19. Van Snick J. Interleukin-6: an overview. Annu Rev Immunol 1990;8:253-278.

20. Anderson JM, Miller KM. Biomaterial biocompatibility and the macrophage. Biomaterials 1984;5(1):5-10.

21. Hart PH, Vitti GF, Burgess DR, Whitty GA, Piccoli DS, Hamilton JA. Potential antiinflammatory effects of interleukin 4: suppression of human monocyte tumor necrosis factor alpha, interleukin 1, and prostaglandin E2. Proc Natl Acad Sci USA 1989;86(10):3803-3807.

22. McNally AK, Anderson JM. Interleukin-4 induces foreign body giant cells from human monocytes/macrophages. Differential lymphokine regulation of macrophage fusion leads to morphological variants of multinucleated giant cells. Am J Pathol 1995;147(5):1487-1499.

23. Nathan CF, Prendergast TJ, Wiebe ME, Stanley ER, Platzer E, Remold HG, Welte K, Rubin BY, Murray HW. Activation of human macrophages. Comparison of other cytokines with interferon-gamma. J Exp Med 1984;160(2):600-605.

24. Reis RL, Mendes SC, Cunha AM, Bevis MJ. Processing and in vitro degradation of starch/EVOH thermoplastic blends. Polym Int 1997;43(4):347-352.

25. Malafaya PB, Elvira C, Gallardo A, San Roman J, Reis RL. Porous starch-based drug delivery systems processed by a microwave route. J Biomater Sci Polym Ed 2001;12(11):12271241.

26. Gomes ME, Ribeiro AS, Malafaya PB, Reis RL, Cunha AM. A new approach based on injection moulding to produce biodegradable starch-based polymeric scaffolds: morphology, mechanical and degradation behaviour. Biomaterials 2001;22(9): 883-889.

27. Espigares I, Elvira C, Mano JF, Vázquez B, San Roman J, Reis RL. New partially degradable and bioactive acrylic bone cements based on starch blends and ceramic fillers. Biomaterials 2002;23:1883-1895.

28. Thavasu PW, Longhurst S, Joel SP, Slevin ML, Balkwill FR. Measuring cytokine levels in blood. Importance of anticoagulants, processing, and storage conditions. J Immunol Methods 1992;153(1-2):115-124.

29. Kinneard PR, Gray CD. SPSS for windows: made simple. Hove, UK: Psychology Press; 1999.

30. Marques AP, Reis RL, Hunt JA. The effect of starch-based biomaterials on in vitro leukocyte adhesion and activation. J Mater Sci Mater Med 2004. Forthcoming.

31. DeFife KM, Yun JK, Azeez A, Stack S, Ishihara K, Nakabayashi N, Colton E, Anderson JM. Adhesion and cytokine production by monocytes on poly(2-methacryloyloxyethyl phosphorylcholine-co-alkyl methacrylate)-coated polymers. J Biomed Mater Res 1995;29(4):431-439.

32. Hagerty RD, Salzmann DL, Kleinert LB, Williams SK. Cellular proliferation and macrophage populations associated with implanted expanded polytetrafluoroethylene and polyethyleneterephthalate. J Biomed Mater Res 2000;49(4):489-497.

33. Schmidt JA, von Recum AF. Macrophage response to microtextured silicone. Biomaterials 1992;13(15):1059-1069.

34. Wiegand F, Kroncke KD, Kolb-Bachofen V. Macrophage-generated nitric oxide as cytotoxic factor in destruction of alginateencapsulated islets. Protection by arginine analogs and/or coencapsulated erythrocytes. Transplantation 1993;56(5): 1206-1212.

35. Anderson JM. Mechanisms of inflammation and infection with implanted devices. Cardiovasc Pathol 1993;2(3):33-41.

36. Bonfield TL, Colton E, Marchant RE, Anderson JM. Cytokine and growth factor production by monocytes/macrophages on protein preadsorbed polymers. J Biomed Mater Res 1992;26(7): 837-850.

37. Yun JK, Defife K, Colton E, Stack S, Azeez A, Cahalan L, Verhoeven M, Cahalan P, Anderson JM. Human monocytemacrophage adhesion and cytokine production on surfacemodified poly(tetrafluoroethylene hexafluoropropylene) polymers with and without protein preadsorption. J Biomed Mater Res 1995;29(2):257-268.

38. Boynton EL, Waddell J, Meek E, Labow RS, Edwards V, Santerre JP. The effect of polyethylene particle chemistry on human monocyte-macrophage function in vitro. J Biomed Mater Res 2000;52(2):239-245.

39. Nakaoka R, Tsuchiya T, Nakamura A. Studies on the mechanisms of tumorigenesis induced by polyetherurethane in rats: production of superoxide, tumor necrosis factor, and interleukin 1 from macrophages cultured on different polyetherurethanes. J Biomed Mater Res 2000;49(1):99-105.

40. Chomyszyn-Gajewska M, Czajkowska B, Blazewicz M, Pamula E, Ptak M. In vitro response of macrophages to a new carbonpolylactide composite for the treatment of periodontal diseases. Biomaterials 2002;23(2):463-470.

41. Ung DY, Woodhouse KA, Sefton MV. Tumor necrosis factor (TNF alpha) production by rat peritoneal macrophages is not polyacrylate surface-chemistry dependent. J Biomed Mater Res 1999;46(3):324-330.

42. Khouw IM, van Wachem PB, de Leij LF, van Luyn MJ. Inhibition of the tissue reaction to a biodegradable biomaterial by monoclonal antibodies to IFN-gamma. J Biomed Mater Res 1998;41(2):202-210.

43. Genassi S, Belardelli F. IFN- $\gamma$ expression in macrophages and its possible biological significance. Cytokine Growth Factor Rev 1998;9(2):117-123.

44. Scheibenbogen C, Andreesen R. Developmental regulation of the cytokine repertoire in human macrophages: IL-1, IL-6, TNF-alpha, and M-CSF. J Leukoc Biol 1991;50(1):35-42.

45. Bostman OM. Intense granulomatous inflammatory lesions associated with absorbable internal fixation devices made of polyglycolide in ankle fractures. Clin Orthop 1992(278):193-199.

46. Haynes DR, Boyle SJ, Rogers SD, Howie DW, Vernon-Roberts B. Variation in cytokines induced by particles from different prosthetic materials. Clin Orthop 1998(352):223-230.

47. Levings MK, Schrader JW. IL-4 inhibits the production of TNF-alpha and IL-12 by STAT6-dependent and -independent mechanisms. J Immunol 1999;162(9):5224-5229.

48. Witsell AL, Schook LB. Tumor necrosis factor alpha is an autocrine growth regulator during macrophage differentiation. Proc Natl Acad Sci USA 1992;89(10):4754-4758.

49. Donnelly RP, Crofford LJ, Freeman SL, Buras J, Remmers E, Wilder RL, Fenton MJ. Tissue-specific regulation of IL-6 production by IL-4. Differential effects of IL-4 on nuclear factorkappa B activity in monocytes and fibroblasts. J Immunol 1993;151(10):5603-5612.

50. Alves CM, Reis RL, Hunt JA. Preliminary study on human protein adsorption and leukocyte adhesion to starch-based biomaterials. J Mater Sci Mater Med 2003;14:157-165.

51. Jaffe WL, Scott DF. Total hip arthroplasty with hydroxyapatitecoated prostheses. J Bone Joint Surg Am 1996;78(12):1918-1934.

52. Geesink R, Hoefnagels N. Eight years results of HA-coated primary total hip replacement. Acta Orthop Belg 1997;63(Suppl 1):72-75.

53. Morscher EW, Hefti A, Aebi U. Severe osteolysis after thirdbody wear due to hydroxyapatite particles from acetabular cup coating. J Bone Joint Surg Br 1998;80(2):267-272.

54. D'Antonio JA, Capello WN, Manley MT, Feinberg J. Hydroxyapatite coated implants. Total hip arthroplasty in the young patient and patients with avascular necrosis. Clin Orthop 1997; 344:124-138. 